\title{
LA GUERRA JUSTA DE FRANCISCO DE VITORIA
}

\author{
Beatriz MALDONADO SIMÁN*
}

RESUMEN: Este artículo tiene por objetivo examinar los títulos jurídicos formulados por Francisco de Vitoria, para dar paso a la guerra justa. El marco de referencia para el análisis de la guerra justa es el descubrimiento de América, la interpretación de las bulas papales de donación dadas a los reyes católicos de España y las implicaciones políticas de la toma de la tierra en el nuevo continente. Con dichos acontecimientos, se sigue la interpretación de la guerra justa no sólo en su dimensión legal, sino en la perspectiva histórico-política. Con base en el pensamiento de orden concreto, se destaca el arraigo medieval que determinó la formulación del concepto de guerra justa. Con ello, se hace una interpretación del impacto contemporáneo que ha tenido la formulación vitoriana de guerra justa empleada por los actores políticos del siglo XXI.

ABSTRACT: The goal of this article is to examine the juristic titles stated by Francisco de Vitoria, with which take place the just war. The reference frame for the just war analysis is the discovery of American Continent, the interpretation of Papal Bull of donation that were gave to the Catholic Kings of Spain and politic implications related with the take of land in the new Continent. With such events, continues the just war interpretation, not only on its legal dimension, but on the historical and politic perspectives. On the basis of concret order thought, it is distinguished the medieval root that establish the formulation of just war concept. It is made an interpretation about contemporary impact that Vitorian formulation has have regarding the just war used for politic actors from XXI century.

RÉSUMÉ: Cet article a comme objectif l'examen des justifications juridiques formulées par Francisco de Vitoria, pour entamer une guerre juste. Le fil de référence de l'analyse de cette guerre juste est la découverte de l'Amérique, l'interprétation des bulles de donation octroyées aux rois catholiques d'Espagne et les implications politiques de l'appropriation de la terre du nouveau continent. Avec le suivi de ces événements, on suit l'interprétation de la guerre juste, d'une part dans une dimension légale et d'autre part dans une perspective historique et politique. A la base de cette pensée d'ordre concret, se détache l'enracinement médieval qui a déterminé la formulation du concept de guerre juste. Il s'ensuit une interprétation de l'impact contemporain qui a eu la formulation vitorianne de guerre juste, employée par les acteurs politique du XXI siècle.

\footnotetext{
* Doctorante en Derecho. Facultad de Estudios Superiores Acatlán. UNAM.
}

Anuario Mexicano de Derecho Internacional, vol. VI, 2006, pp. $679-701$ 
SUMARIO: I. Presentación. II. Las bulas alejandrinas. III. La toma de la tierra en el marco de la conquista de América. IV. La guerra justa de Vitoria. V. Conclusión. VI. Bibliografia.

\section{PRESENTACIÓN}

El criterio legalista sería muy sano para entrar directamente al análisis del concepto de guerra justa tal como lo elaboró Francisco de Vitoria, sin embargo, hay muchos elementos histórico-políticos en torno a ese concepto que requieren de otras interpretaciones.

Veamos en qué consiste el concepto de guerra justa. De acuerdo con Vitoria la guerra justa tendría lugar ante la violación de algún título jurídico legítimo (por él formulados) "por los cuales los bárbaros del nuevo mundo pudieron venir a poder de los españoles". Así, la guerra justa constituía el medio indirecto para la ocupación legítima (más que legítima, era legal) de España en América.

Hechas las anteriores observaciones de orden formal, el empleo del concepto de guerra justa en este trabajo busca determinar su impacto marcado por una formulación que aún respondía al pensamiento medieval. La referencia obligada de este análisis es el descubrimiento de América, en donde además es curioso observar cómo la guerra justa en su concepto, llegó mucho después de la consumación de los hechos: al menos en el continente americano tuvimos que esperar casi medio siglo tras el descubrimiento, a que la escolástica española y el papado contaran con el argumento jurídico para legitimar su presencia en América.

Deducir las consecuencias del pensamiento vitoriano vinculado al mundo medieval, con la interpretación de las bulas alejandrinas, todo en el marco que proporcionaba la gran toma de la tierra americana, es de capital importancia para examinar las concepciones de derecho natural atribuidas a Vitoria y las repercusiones de su pensamiento hasta nuestros días.

Así, el análisis de los títulos jurídicos y de la guerra justa que pretende este estudio, se hará a la luz de los elementos arriba mencionados, pues el título legítimo por el que se llega a la guerra justa por sí mismo, podría ser presentado de manera autónoma o independiente, al margen de toda consideración política o moral, y arrojar respuestas estrictamente jurídicas, incluso plausibles para el momento histórico que se vivía. Sin 
embargo, sabemos que una norma o un cuerpo de normas se refiere a algo más que a sí misma y no puede, desde luego, realizarse sin la voluntad de alguien. Por ello, también es capital examinar por un lado a qué se refiere el término de guerra justa, y quién ha tenido interés para su realización.

Con el telón del cristianismo, el ocaso del siglo XV anunciaba el conflicto que representaba la presencia militar, la exacción y explotación de la fuerza de trabajo de los indios, con la justificación jurídica y teológica; fue un desafío para muchos. Primero, le hicieron frente con la guerra justa, después con la pacificación. Pero a fin de cuentas, este continente quedó marcado por el mundo medieval y los intereses contrarrevolucionarios. No hemos sido producto del progreso de la modernidad, sino de su crisis y de sus ideologías. La guerra justa inauguró este camino.

\section{LAS BULAS ALEJANDRINAS}

El examen formal de las bulas papales ${ }^{1}$ en su calidad de bulas pontificias sobre el descubrimiento, ${ }^{2}$ puede ubicarse en el marco de la doctrina omni-insular.

Las Bulas Alejandrinas de Partición, de 1493, constituyen una de las últimas aplicaciones prácticas de una vieja y extraña teoría jurídica, elaborada

1 Para consultar el texto original de las bulas, véase: Apéndice I: Alejandro VI: Bulas de la concesión de las Indias a los Reyes Católicos. Bula "Inter cetera" del 3 de mayo de 1493, Bula "Eximiae Devotionis" del 3 de mayo de 1493, Bula "Inter cetera" del 4 de mayo de 1493, Bula "Dudum siquidem" del 26 de septiembre de 1493, Bartolomé de las Casas, Tratados, México, FCE, 1997, t. II, Biblioteca Americana, núm. 42, pp. 1277-1290.

2 Castañeda, Paulino, "La interpretación teocrática de las bulas alejandrinas", Anuario Mexicano de Historia del Derecho, México, Universidad Nacional Autónoma de México, Instituto de Investigaciones Jurídicas, vol. V, 1993, pp. 31-32. El autor indica: "La primera Inter caetera (3.V.1493) hace donación a los reyes católicos de las islas y tierras descubiertas y que se descubrieran navegando hacia occidente... La Eximie devotionis (3.V.1493) en la que extracta la primera parte de la anterior, y reproduce literalmente, con ligeras variantes, la segunda parte de la misma en la que concedía los mismos derechos y privilegios que tenían los reyes portugueses. La segunda Inter caetera (4.V.1493) reproduce a la letra, con leves variantes, la primera parte de la Inter caetera primera y establece una línea de demarcación, entre las zonas reservadas a los posibles descubrimientos de castellanos y portugueses, a cien leguas, dirección norte-sur, al oeste de las Azores y Cabo Verde. Omite los privilegios. La Dudum siquidem (26.IX.1493) concedía a los reyes de Castilla las tierras que se descubrieran al este, al sur, y al oeste de la India con tal de que no estuviesen ocupados de hecho por otro príncipe cristiano". Los nombres en latín de ambas fuentes son citados tal como aparecen en las obras consultadas. 
explícitamente en la corte pontificia a fines del siglo XI, enunciada por primera vez en el año 1091 por el Papa Urbano II [pero que quizá traza su paternidad a Gregorio VII] y conforme a la cual todas las islas pertenecen a la especial jurisdicción de San Pedro y de sus sucesores, los pontífices romanos, quienes pueden libremente disponer de ellas. Esta teoría... bajo el nombre de doctrina omni-insular es, sin duda alguna, una de las elaboraciones más originales y curiosas del derecho público medieval. ${ }^{3}$

Weckmann sostiene que la supremacía espiritual de Roma se desarrolla en torno a las Escrituras, a la literatura patrística, a los concilios y a la doctrina eclesiástica particular. "Pero la discusión sobre los privilegios temporales del papado originados históricamente en fechas dadas es, indiscutiblemente, una cuestión de derecho". ${ }^{4}$ Es entonces la intervención del papado en asuntos temporales donde el autor citado encuentra la base jurídica para justificar la acción de Alejandro VI en 1493: "Por consiguiente, a la pregunta ¿cuál fue la naturaleza de la donación pontificia y en qué fundamentos jurídicos se apoyaba? Respondemos: Se trata de una verdadera donación hecha por el pontífice, considerado como dueño temporal de la Tierra, con vistas a su misión espiritual". ${ }^{5}$

La Edad Media se caracterizó por la ambigüedad temporal del papado y espiritual del monarca. Pero en sentido estricto, podríamos considerar a las bulas alejandrinas como el fundamento jurídico de derecho público de la época, sin embargo, en sentido amplio la cuestión rebasaba la posible denotación jurídica, pues el hecho del descubrimiento supera a las bulas.

A mi juicio, el único elemento que se impone es que ese fundamento jurídico de derecho público fue dado por quien aún representaba la unidad de la cristiandad occidental: el papa.

Por el sujeto, se trataba pues de la única autoridad con jurisdicción universal para validar o arbitrar semejante hallazgo. Por el objeto virtual, aún no claramente definido por la cartografía europea, se trataba de islas grandes o chicas, pero no de continentes. Y por la relación jurídica que se establece por aquella donación papal, se refería a la ocupación de islas y tierra firme, entendida ésta como masa territorial insular. Hay que

3 Weckmann, Luis, Constantino el Grande y Cristóbal Colón. Estudios de la supremacía Papal sobre islas, 1091-1493, 2a. ed., México, FCE, 1992, p. 24.

4 Ibidem, p. 18.

5 Castañeda, Paulino, op. cit., nota 2, p. 35. 
agregar que en la mente medieval la donación incluía lagunas con cíclopes, sirenas, codiciadas cascadas de oro y bárbaros desnudos carentes de toda cultura, dispuestos a ser evangelizados.

Salvo las observaciones anteriores, me atengo a las recomendaciones de Weckmann - respecto de la interpretación formal — que hay que hacer de las bulas papales, es decir, se trata de documentos medievales. ${ }^{6}$

Por otro lado, Weckmann señala que la interpretación hecha a las bulas tiene errores de perspectiva pues se les ha examinado desde un punto de vista moderno. Por ejemplo, a fines del siglo $\mathrm{XV}$, los términos interpretativos de soberanía, arbitraje o derecho internacional, no formaban parte del patrimonio de la cultura jurídica. Otro error ha sido su interpretación como documentos aislados, e incluso señala que pocas veces se ha hecho un estudio comparativo de las bulas portuguesas, con las que de igual manera, se concedió derechos de ocupación a Portugal en islas africanas; es decir, hay muchos precedentes para entender su verdadero significado. Por último, además de ser documentos medievales, no está ni en la mente del papa ni en la de Colón, que los hallazgos se trataran de un continente.

En suma, el proceder formal papal queda ilustrado con lo siguiente:

La figura del más discutido de los Papas renacentistas, Rodrigo Borja, aunada al descubrimiento de todo un hemisferio del cual se dispone en un espectacular 'trazo de pluma' basta para cegar al más objetivo de los historiadores. La proximidad de la Reforma, la existencia en la época de innegables abusos entre el clero, y la vida ligera característica del Renacimiento romano hacen el resto... Se olvida que la cancillería Papal es una de las instituciones más metódicas y rutinarias de Europa y que la redacción de las bulas papales sigue, dentro de lo factible, y preferentemente, rutas ya trazadas y moldes tradicionales tomados de previos documentos. El hecho de que el Nuevo Mundo haya sido descubierto cuando Alejandro VI ocupaba el solio pontificio fue algo meramente fortuito y no por otra razón que la anterior el mismo Pontífice fue llamado a disponer de las nuevas tierras.

Probablemente, de haberse descubierto el Nuevo Mundo de la misma manera, cien años antes, en 1392 bajo Bonifacio IX, o doscientos años antes, en 1292 bajo Nicolás IV, y dado que tal descubrimiento hubiera seguido cronológicamente al de las islas portuguesas del África, la 
redacción de las bulas pontificias pertinentes hubiera sido, básicamente, la misma y la única probable alteración, aparte del nombre de los monarcas destinatarios y del pontífice signatario, hubiera sido la sustitución del nombre de Cristóbal Colón por el de otro descubridor. ${ }^{7}$

La postura anterior asegura que la cancillería pontificia se encuentra vinculada a viejas fórmulas insertas siempre en la redacción de documentos, que en la lógica de las bulas alejandrinas, responde — según el autor citado - a una vieja teoría jurídica que data del siglo XI, es decir, la doctrina omni-insular.

Esta doctrina a la luz del derecho público medieval está sancionada por la costumbre y además llega a constituir derecho positivo, ya que su indiscutible aceptación "es la razón que debemos dar al por qué, en los sucesivos actos de disposición de islas, que el papado lleva a cabo en los siglos XIII, XIV y XV, no existe mención específica alguna de la doctrina. Como principio aceptado en el derecho público de la época, ya no existe necesidad, para el papado de esos siglos, de referir más el derecho pontificio a su fuente original". 8

Así, "creemos, en suma, que el sentido con que fue dada la bula era el que aún predominaba en la curia romana. Creemos en un título de las bulas, fundado en la doctrina teocrática, doctrina de larga tradición, sentencia común, y presente en la conciencia de los reyes españoles, consejeros y conquistadores". 9

La Bula Inter Cetera del 3 de mayo de 1493 se refiere al temerario viaje de Colón: "Y navegando él y los suyos con el auxilio divino, y poniendo por obra extremada diligencia, a través de las regiones occidentales del mar Océano y en dirección hacia los Indios, como es fama, descubrieron ciertas islas remotísimas, así como tierras firmes, que hasta entonces nadie había conocido". Alejandro extiende a los reyes de España la donación de las tierras para predicar el evangelio entre los naturales. Aclara que con esta bula se da la posesión de las tierras, en tanto no estén en posesión de ellas príncipes cristianos. La segunda Bula Inter $\mathrm{Ce}$ tera del 4 de mayo de $1493^{10}$ insiste en la mención de las islas e introduce la famosa línea alejandrina. "El Papa no intenta con esta línea 'dividir

7 Idem.

8 Idem.

9 Castañeda, Paulino, op. cit., nota 2, p. 35.

10 Weckmann, op. cit. nota 3. Cita a esta bula como despachada en junio del mismo año. 
al mundo' — de cuya esfericidad, posiblemente, no se había enteradoen dos partes, y entregarlo así, en proporciones iguales, a las dos potencias ibéricas". 11

Por otro lado, como se ha dicho, las bulas se referían a las islas y terra firma. Esta última significaba masa territorial insular y se utilizaba para describir las costas o barras de arena mayores en contraposición a las costas pequeñas y menores. ${ }^{12}$ Sobre las islas, Fernando Benítez señala que la Edad Media vivía soñando con islas, pues los continentes son grandes y complejos "una isla es una realidad claramente delimitada, una invitación al aislamiento y una manera de escaparse del mundo conocido. Una isla es también un pequeño universo original, un castillo rodeado de un foso, un lugar sui generis, sin fronteras, sin vecinos molestos, autónoma y redondo". ${ }^{13}$

Sin duda, los sueños insulares de Colón, y de todos los temerarios navegantes de la época, fueron influidos por Marco Polo, y además, por qué no, por una necesidad que bien data de la polis, de encontrar todo en pequeño y bajo control, con un orden definido.

Esto confirma que:

Existe efectivamente un derecho de gentes del período de la visión preglobal del mundo. Pero sus concepciones del mundo y de los pueblos permanecían en lo mítico y no resistieron a la ilustración geográfica y a las mediaciones científicas de acuerdo con la visión global del mundo que surgió después del siglo XVI. La tierra o el mundo era concebido como un círculo, un orbis. ${ }^{14}$

Entonces por un lado, las bulas hacían mención a islas —objeto virtual de las bulas - y no a continentes, situación que por un lado no podemos reprochar en virtud del estado que guardaba la cartografía europea de la época. Por otro lado, sobre la autoridad que las dictó, el papado detentaba la jurisdicción en la materia. El asunto en donde sí hay que enfatizar para deducir los efectos políticos investidos de juridicidad, es la finalidad u objetivo de las bulas: la predicación. En esta predicación está

11 Ibidem, p. 208.

12 Ibidem, p. 214.

13 Benítez, Fernando, La ruta de Hernán Cortés, 2a. ed., México, FCE, 1956, p. 13

14 Schmitt, Carl, "El Nomos de la tierra. Cinco corolarios a modo de introducción", Carl Schmitt, Teólogo de la política, México, FCE, 2001, pp. 471 y 472. 
el meollo de las elaboraciones de la guerra justa que desarrollaría Vitoria.

\section{LA TOMA DE LA TIERRA EN EL MARCO DE LA CONQUISTA DE AMÉRICA}

Una interpretación de la ocupación de América desde el punto de vista geopolítico, la encontramos en el pensamiento de Carl Schmitt. Para este autor, el nuevo mundo representó un espacio libre para la ocupación y expansión europeas; no estamos entonces frente a simples delimitaciones geográficas y al trazado de líneas de meridianos, sino al contenido de las ideas políticas acerca del espacio y su ordenación. ${ }^{15}$ Como se verá, la justificación de la toma de la tierra americana es reducida por Vitoria al problema de la guerra justa.

Sin importar la forma, es decir, como resultado de grandes migraciones o de guerras de conquista, para Schmitt, la toma de la tierra es un hecho jurídico histórico y no una construcción del pensamiento y precede incluso, a la distinción entre derecho público y privado. Así, la toma de la tierra crea el título jurídico más radical que existe, no tratándose desde luego de una ley positiva. ${ }^{16}$

Para Schmitt, la línea alejandrina es la primera línea global (establecida en la segunda Inter Cetera) después de conocida América, que transcurre desde el polo norte al polo sur, a cien millas al oeste del meridiano de las islas Azores y del Cabo Verde.

A esta línea global, le sigue la trazada por el tratado de partición de Tordesillas del 7 de junio de 1493 entre España y Portugal, confirmada por Julio II: "que está algo desplazada hacia el oeste y transcurre aproximadamente por el medio del Océano Atlántico [a 370 millas al Oeste de Cabo Verde]. En este tratado, las dos potencias católicas tomaron el acuerdo de que todas las nuevas tierras descubiertas al Oeste de la raya pertenecieran a los españoles y las descubiertas al Este de la raya a los portugueses".

A diferencia de la "línea global", la raya:

15 Schmitt, Carl, El Nomos de la tierra en el "Derecho de Gentes del Ius publicum europeam", trad. de Dora Schilling Thou, Granada, Comares, 2002, p. 59.

16 Schmitt, Carl, op. cit., nota 14, pp. 467 y 468. 
Presupone que dos soberanos, que reconocen la misma autoridad espiritual también en el aspecto del Derecho de Gentes, llegan a un acuerdo sobre la adquisición de tierra de soberanos y pueblos heterodoxos. Aun cuando es un acto contractual el que lleva al establecimiento de la raya, siempre se halla en el fondo la autoridad de un ordo común... que como instancia de Derecho de Gentes, distingue el suelo de soberanos y pueblos no cristianos de aquél de los cristianos. Si bien el Papa no adjudicaba en aquel entonces la propiedad de las tierras, sino únicamente territorios para la actividad misionera, también esto era expresión de una ordenación del espacio que distinguía el ámbito de poder de soberanos y pueblos cristianos de territorios de soberanos no cristianos... la raya presupone así que soberanos y pueblos cristianos tienen derecho a que el Papa les adjudique un encargo de misión. ${ }^{17}$

Podemos decir, entonces, que el descubrimiento de las islas (América) y su donación a los reyes de España por parte del papado, se adscribe a la lógica insular mediante la cual San Pedro posee jurisdicción sobre todas las islas, y competencia para adjudicarlas en misión.

Es decir, la parte formal, y también la trascendencia política del descubrimiento deben interpretarse en el contexto medieval y papal de la época, es decir, se deliberó conforme al orden concreto.

Hecha la distinción entre raya y línea global, podemos decir que ésta en su arraigo medievalista, tiene no obstante, alcances políticos relevantes, pues sin saber que se trataba de un gran continente, se adelanta a la concepción del mundo marcando las pautas para la ocupación europea en suelo americano. El pensamiento en líneas globales representa para Schmitt una fase en la evolución histórica de la conciencia humana del espacio cuyo inicio se da con el encuentro del Nuevo Mundo. ${ }^{18}$

Por otro lado, no sólo se trataba de asegurar la pacífica convivencia entre las potencias ibéricas, confirmada por el Tratado de Tordesillas, sino también de la posición de la figura papal, al mantenerse vigente respecto de la protección y aseguramiento de dichas tierras.

Recordemos que el pontífice romano, como señor temporal (no como cabeza de la Iglesia universal) ofrecía la protección de San Pedro. La búsqueda que hacían "reyes y príncipes, que gobernaban sobre lo que hoy llamaríamos Estados soberanos, prestan homenaje a otros gobernan- 
tes, remitiéndoles sus tierras y recibiéndolas de nuevo en feudo, reconociendo con ello su vasallaje". ${ }^{19}$

El vasallaje constituyó una de las relaciones políticas y temporales más importantes del complejo entramado medieval, en la que el valor de la protección era superior al de la libertad.

Para nuestro tema, es importe destacar el vasallaje ejercido en los reinos ibéricos. En 1073 y 1077 Gregorio VII (quien ocupó el solio pontificio de 1073 a 1085) formula títulos de supremacía sobre la península ibérica en cartas dirigidas a los príncipes españoles. ${ }^{20}$

Para la reconquista de las nuevas tierras, Gregorio también prometió a los españoles el Dominium a condición de que fueran ex parte sancti Petri, y enviaran el respectivo denarius. La supremacía Papal también se asentó en los reinos de Aragón, Cataluña y Valencia en 1905 puestos en vasallaje por Pedro I de Aragón; los condes de Portugal y Castilla emergen en la historia como vasallos del reino de León. ${ }^{21}$

Como vemos, la soberanía recibida por los reyes españoles para las tierras de ultramar, no sólo se trataba de un Dominius possesionis, sino que confirmaba que los símbolos de poder provenían de la autoridad autorizada para ello. Con lo anterior podemos relacionar algunas cuestiones:

Primero, la lucha que sostenían los reinos españoles en la reconquista era apoyada por el papado, quien tres siglos antes del descubrimiento les otorgaba protección. El denarius recibido por el papado no cesó y debió incrementarse con el descubrimiento americano.

Segundo y a partir de lo anterior, la iglesia española nunca estuvo tan vinculada al papado como durante el descubrimiento americano. "Después de dar cima a la Reconquista, España se convirtió... en un Estado-Iglesia, en el que los intereses de la Corona y de la Iglesia se identificaban, formando un todo único indivisible". ${ }^{22}$ España se convirtió en el bastión de la contrarreforma.

19 Weckmann, Luis, El pensamiento político medieval y los orígenes del derecho internacional, 2a. ed., México, FCE, 1993, p. 57.

20 Ibidem, p. 65.

21 Ibidem, p. 68.

22 Cfr. Grigólevich, J., La Iglesia católica y el movimiento de liberación en América Latina, Moscú, Progreso, 1984, p. 87. 
Y, tercero, en la época medieval al recibirse la investidura de poder por la autoridad papal, tenemos que a pedido español la adjudicación de las nuevas tierras, perseguía en el naciente derecho internacional producto de las circunstancias, el reconocimiento del Dominius possesionis en América, pero además, de acuerdo con la Doctrina del Dominium ${ }^{23}$ medieval, pretendió el Dominius proprietatis sentando las bases del dominio exterior español no sólo frente a los portugueses, sino frente al mundo entero, esto es, estaba en camino de un derecho de propiedad indivisible: el Imperium, como derecho público, y como la primera toma de la tierra en suelo americano, modificando la ordenación espacial preexistente, y desde luego, creando un nuevo orden.

En este contexto, con las rayas distintos soberanos del mismo orden acuerdan sus diferencias.

Lo esencial es que, dentro del territorio cristiano, las guerras entre los soberanos cristianos son guerras acotadas, que se diferencian de las guerras contra soberanos y pueblos no cristianos. Las guerras internas... se desarrollan al margen de la misma ordenación general que abarca a ambas partes combatientes. ${ }^{24}$

Las líneas globales en cambio, deberían buscar a la larga la supremacía exterior cristiana frente a cristianos o no, y en este sentido, lógico era que la nueva guerra en América tuviera como medio de ocupación la predicación.

La predicación se adscribe a la lógica medieval de toma de tierra según el antiguo derecho medieval, es decir, bajo el mandato de misión para la asignación de tierras a cristianos. No obstante, esta fórmula resolvió en su primera fase la ocupación de América, pues el Nuevo Mundo representaba un desafío jurídico para aquel derecho. Es así como la libertad para ocupar tierras americanas radicaba en el uso indiscriminado de la violencia. Sobre el particular, ya no regía el derecho antiguo ${ }^{25}$ salvo el vehículo de ocupación: la predicación.

23 Se ha considerado a la Doctrina del Dominium, como la llave de la teoría política del estado de aquel tiempo. Cfr. Weckmann, Luis, op. cit., nota 19 pp. 112 y ss.

24 Schmitt, Carl, op. cit., nota 14, p. 478.

25 Schmitt, Carl, op. cit., nota 15, p. 64. 
Para lo anterior, fueron invaluables los servicios que prestó Vitoria en su elaboración ad hoc de la guerra justa, pues con ello se tornó jurídica la toma de suelo ajeno no libre:

Fue una ordenación del espacio totalmente distinta la que puso fin al derecho de gentes medieval en Europa. Esta ordenación surgió con el Estado europeo centralizado, territorialmente cerrado, que era soberano frente al emperador y al Papa, pero también frente a cualquier vecino, y que tenía abierto un espacio libre ilimitado para adquisiciones de tierra en ultramar. Los nuevos títulos jurídicos, característicos de este nuevo derecho de gentes, pero totalmente desconocidos a la Edad Media cristiana, son el descubrimiento y la ocupación. La nueva ordenación del espacio ya no está basada en un asentamiento seguro, sino en un equilibrio. ${ }^{26}$

Los nuevos espacios además de desafiar el viejo orden, exigían generar teorías a la altura del descubrimiento. Este fue el trabajo de Vitoria.

\section{LA GUERRA JUSTA DE VITORIA}

Para dar fuerza legal a la gran toma de la tierra, entraron a colación instituciones medievales acompañadas de un fuerte espíritu cristiano. No sólo se empleó una teoría de salvación cristiana, sino también una filosofía de superioridad predestinada que a nombre de la cristiandad, justificaría a manos de hábiles argumentaciones escolásticas españolas el hecho de la conquista.

Dichas argumentaciones tendrían que edificarse a partir de principios teológicos y de la recuperación de un derecho natural etiquetado con la alteridad de la cosmovisión española de la época.

Desde ahora hay que enfatizar que la segunda escuela escolástica española suministró el espíritu para la formulación de la guerra justa, ad hoc, al hecho del descubrimiento, aunque como veremos, el propio descubrimiento es ignorado por Vitoria:

Desde luego, esta escuela está más conectada con el tomismo y el derecho canónico, que con el Corpus Iuris y sus intérpretes... esta escuela se refiere a la preferencia a temas de filosofía del derecho o de derecho público, 
que no se prestan tanto a la amalgamación con la literatura romanista de aquella época, cada vez más centrada en temas de derecho privado. ${ }^{27}$

El rompimiento de la escolástica española con el derecho romano, bien se debe a que éste proporcionaba títulos jurídicos de adquisición de propiedad de acuerdo con el derecho de gentes, en particular la occupatio, descontextualizado del aparato teológico de la época, que exigía a toda costa la predicación como medio de ocupación. Además, para el derecho romano a la esclavitud reconocida por el derecho de gentes como resultado de la guerra, había que agregar la esclavitud natural aristotélica adaptada en el pensamiento español, particularmente por Juan Ginés de Sepúlveda, en relación a que el indio inferior debe ser esclavo del español superior.

Debido a la conexión tomista con la segunda escolástica española, haremos algunas observaciones.

\section{El pensamiento tomista}

Tomás de Aquino (1225-1274) 28 en su Tratado de la justicia, capítulo I. Del derecho, artículo 3, se pregunta: Si el derecho de gentes se identifica con el derecho natural.

Parece que el derecho de gentes se identifica con el natural, porque:

a) No todos los hombres están de acuerdo sino en lo natural; pues dice el jurisconsulto que 'el derecho de gentes es aquél que siguen todas las naciones'. Luego el derecho de gentes es natural.

b) Además, la servidumbre entre los hombres es natural, pues algunos son naturalmente siervos, como dice el filósofo en la Política, libro 1 , cap. 3 y 4 . Pero 'la servidumbre pertenece al derecho de gentes', como dice Isidoro en las Etimologías, libro 5, cap. 6. Luego el derecho de gentes es natural.

c) Finalmente, el derecho, como lo hemos dicho, se divide en natural y positivo. Pero el derecho de gentes no es positivo, pues no todos los países se pusieron de acuerdo por un común consentimiento para establecerlo. Luego el derecho de gentes es natural.

27 Margadant, Guillermo, La segunda vida del derecho romano, México, Porrúa, 1980, pp. 220 y 221 .

28 Aquino, Tomás de, Tratado de la ley, tratado de la justicia, gobierno de los príncipes, México, Porrúa, 2000, pp. 119 y 120. 
Ahora bien, en la distinción que hace Tomás de Aquino entre el derecho de gentes y el derecho natural, encontramos la relación de alteridad que Sepúlveda desarrolla en su obra Democrates Alter de 1547, ${ }^{29}$ para justificar la superioridad natural española frente a los indios. Veamos qué dice Tomás de Aquino:

Como hemos dicho, el derecho o lo justo natural está adecuado o conmensurado al otro. Y esto puede darse de dos maneras: primera, tomado absolutamente, como por ejemplo, un macho por naturaleza está adecuado a la hembra para procrear, y el padre lo está al hijo para alimentarlo. Segunda, puede algo estar conmensurado a otra cosa naturalmente o absolutamente hablando, sino por sus consecuencias. ${ }^{30}$

Aquí está la conmensurabilidad. Más adelante señala "el que un hombre sea siervo y no otro, hablando absolutamente, no es de ninguna razón natural; lo es únicamente por cierta utilidad que puede seguírsele de que sea gobernado por otro más sabio, y que puede también seguírsele al más sabio al ser ayudado por el otro, como dice la Política, libro 1, cap. 5".31

Entonces, ser esclavo no encierra razón natural, sino utilidad: para el caso español, a las jugosas consecuencias de la esclavitud de tres siglos derivada del derecho de gentes, se unió la esclavitud conmensurada por lo justo natural. Lo inhumano de la esclavitud se compensó por la humanidad más elevada de los conquistadores.

Por otro lado, el tomismo proporcionaba el marco general para formular el concepto de guerra justa, mismo que fue reelaborado por Vitoria con sus nuevos ingredientes de moderno derecho de gentes: agregando por un lado, el libre comercio natural y común a todas las naciones, y

29 Juan Ginés de Sepúlveda es autor de la obra Democrates Alter. Tratado sobre las justas causas de la guerra contra los indios, publicada en 1547 en la que expone su pensamiento sobre la guerra que libran los españoles en América. Ante las noticias recibidas en España sobre el maltrato a los indios, Carlos V convocó a teólogos, juristas y letrados a deliberar sobre la forma y las leyes apropiadas para predicar la fe católica en las nuevas tierras. La reunión tuvo lugar en Valladolid en 1550 en la que Ginés de Sepúlveda y Fray Bartolomé de las Casas discutieron el asunto durante cinco días. Fray Domingo de Soto realizó el Summario respectivo del que destacan entre otros: la temática que se adoptó para la discusión no fue la deliberación sobre las leyes para la prédica, sino si era lícito hacer la guerra antes del anuncio evangélico. Cfr. Juan Ginés de Sepúlveda, Tratado sobre las justas causas de la guerra contra los indios, México, FCE, 1996.

30 Tomás de Aquino, op. cit., nota 28, p. 119.

31 Ibidem, p. 120. 
por la otra la predicación. Oponerse al libre comercio o a la prédica eran causa de guerra justa. Según Tomás de Aquino (2-2 q.40 a.1):

Tres cosas se requieren para una guerra justa. Primera la autoridad del príncipe, por cuyo mandato se ha de hacer la guerra... Se requiere en segundo lugar justa causa, a saber, que quienes son impugnados merezcan por alguna culpa esa impugnación. Por eso dice San Agustín: 'Suelen llamarse guerras justas las que vengan injurias'... Finalmente, se requiere que sea recta la intención de los combatientes: que se intente o se promueva el bien o se evite el mal. Por lo cual, dice San Agustín: 'Entre los verdaderos adoradores de Dios, las mismas guerras son pacíficas, pues se mueven por deseo de paz, no por codicia y crueldad, para que sean frenados los malos y favorecidos los buenos'. ${ }^{32}$

En esa ortodoxia teológica podemos incluir, como se ha dicho, la concepción del mundo como un círculo, un orbis, cuya protección política fueron las limes, una gran muralla cuyo sentido era separar un orden de un desorden. En el caso español, todo lo que estaba fuera de casa, lejano, procul, interpretado como lo hizo Sepúlveda, diverso, de diferente religión, representaba un desorden que había que ordenar. Sumemos a lo anterior, que la guerra justa librada por los españoles, no era como aquellas acotadas al interior del viejo ordo medieval, en donde el asentamiento estaba dado por el derecho de la época, al contrario, elegidos para la gran empresa americana, combatían a nombre de la cristiandad, fuera de casa, lejos.

Por tanto, no se trataba de una guerra pacifica, sino de una guerra justa, que de acuerdo con Tomás de Aquino requería del mandato del príncipe, que los impugnados sean culpables de alguna injuria (hoy agresión) y que exista recta intención de los combatientes, esto es, que se procure el bien y se evite el mal. Con todo este arsenal de conceptos, veamos el proceder de Vitoria.

\section{Marco de referencia de la guerra justa}

El universalismo científico de la época en que se descubre América, estaba en manos de la teología, y por ello como lo expresó Vitoria en sus

32 Suma Teológica de Santo Tomás de Aquino, trad. de Francisco Barbado Viejo, Madrid, Universidad de Salamanca, MCMLIX, t. VII, Biblioteca de Autores Cristianos, p. 1075. 
Reelecciones, "De la potestad Civil”, en la primera frase dice: "El oficio del teólogo es tan vasto, que ningún argumento, ninguna disputa, ninguna materia, parecen ajenos a su profesión". ${ }^{33}$ En este sentido, las premisas de valor de la ciencia jurídica quedaban implícitas en el método dialéctico de análisis y síntesis de los problemas jurídicos creados por los juristas escolásticos de los siglos XI y XII; premisas producidas por las contradicciones de la situación histórica de la sociedad europea. Apoyándose en aquella escolástica la búsqueda por forjar un nuevo análisis, estuvo marcado por los trastornos que separaron las jurisdicciones eclesiástica y secular. ${ }^{34}$ Este es, entre otros, el marco en el que hay que explicarse la producción vitoriana.

Por lo anterior, la elaboración del derecho de conquista o título jurídico, por el que se llegaba a la guerra justa, no pudo escapar al trabajo de un teólogo español como Vitoria, pues además, el hecho histórico implicaba enormes dimensiones políticas:

La Orden de Santo Domingo, a la que pertenecía Vitoria, y las otras Órdenes religiosas que ejercían actividades en las Indias eran los órganos cumplidores del encargo eclesiástico de la misión, del que, según el iure gentium, podía derivarse el título legítimo para una Conquista seglar. Por lo tanto estas Órdenes eran asimismo órganos del Papa y de la Iglesia como autoridad, basada en el Derecho de Gentes, de la Respublica Christiana y tomaban muy en serio su encargo eclesiástico frene a las autoridades seglares y los funcionarios del gobierno español. ${ }^{35}$

3. Las Reelecciones del Estado, de los indios y del derecho de la guerra

En 1538 apareció la obra Reelecciones del Estado, de los indios, y del derecho de la guerra de Francisco de Vitoria. En dicha obra formula los títulos jurídicos para legitimar la ocupación española en América; uno de esos títulos se refiere a la libre misión. Esbozaremos algunos puntos de las Reelecciones... hasta llegar al asunto capital.

33 De Vitoria, Francisco, Reelecciones del estado, de los indios y del derecho de la guerra, México, Porrúa, 1985, p. 2

34 Berman, Harold, J., La formación de la tradición juridica de Occidente, México, FCE, 1996, pp. 169 y ss.

35 Schmitt, Carl, El Nomos de la tierra, cit., nota 15, p. 88. 
Vitoria agrupa los llamados: Títulos no legítimos por los cuales los bárbaros del nuevo mundo pudieron venir a poder de los españoles. Los títulos ilegítimos son siete: el dominio universal del emperador; la autoridad universal y temporal del sumo pontífice romano; el derecho de descubrimiento; la renuncia de los indios a abrazar la fe cristiana; los pecados de los indios; la enajenación de la soberanía; y la predestinación divina.

Por otro lado, formula los Títulos legítimos por los cuales pudieran venir los bárbaros a poder de los españoles. Aquí tenemos siete títulos legítimos: el derecho de sociedad natural y comunicación; la predicación del evangelio; la protección de los convertidos a la fe cristiana; dar un príncipe cristiano a los conversos; los sacrificios humanos y la antropofagia; la elección verdadera y voluntaria; y los tratados de alianza.

En la época eran frecuentes los argumentos biológicos, pero Vitoria con naturalidad sostiene que la libre misión y el libre comercio son los títulos jurídicos de la guerra justa, y con ello el derecho de ocupación para el avasallamiento de los indios. Sin embargo, observemos que "el hecho de que los españoles profesen la religión cristiana no les confiere un derecho inmediato a la toma de las tierras de soberanos y pueblos no cristianos. El derecho a la toma de una tierra surge, según Vitoria, únicamente de modo indirecto, es decir, a través de la argumentación de la guerra justa". ${ }^{36}$ Y la guerra justa tendrá lugar ante la oposición de los indios a la prédica y al libre comercio. El rechazo al anuncio de la fe y al libre comercio representaban injuria, que justificaba la guerra.

Sobre el libre comercio tenemos lo siguiente

1. El primer título puede nombrarse de la sociedad y comunicación natural:.. Los españoles tienen derecho de recorrer aquellas provincias y de permanecer allí, sin que puedan prohibírselo los bárbaros... Por derecho natural, comunes a todos son las aguas corrientes y el mar; lo mismo los ríos y los puertos; y las naves por derecho de gentes es lícito atracar a ellos... parecen públicas esas cosas, luego nadie puede prohibir el uso de ellas. De donde se sigue que harían injuria a los españoles los bárbaros, si se lo prohibieren en sus regiones... Es lícito a los españoles comerciar con ellos, pero sin perjuicio de su patria, importándoles los productos de que carecen y extrayendo de allí oro y plata u otras cosas en que ellos abundan; y ni sus príncipes pueden impedir a sus súbditos que comercien con 
los españoles ni, por el contrario, los príncipes de los españoles pueden prohibirles el comerciar con ellos... Si los bárbaros quisieran negar a los españoles las facultades arriba declaradas de derecho de gentes, como el comercio y las otras cosas dichas, los españoles deben, primero con razones y consejos, evitar el escándalo y mostrar por todos los medios que no vienen a hacerles daño, sino que quieren amigablemente residir allí y recorrer sus provincias sin daño alguno para ellos... Más si, dada razón de todo, los bárbaros no quieren acceder, sino que acuden a la violencia, los españoles pueden defenderse... porque lícito es rechazar la fuerza con la fuerza... y si padecen injuria, pueden con la autoridad del príncipe vengarla con la guerra, y llevar adelante los demás derechos de guerra. Se prueba. Porque la causa de la guerra justa es rechazar y vengar una injuria, como queda dicho siguiendo a Santo Tomás; pero los bárbaros, negando el derecho de gentes a los españoles [derecho de libre comercio] les hacen injuria; luego si es necesaria la guerra para adquirir su derecho, pueden lícitamente hacerla. ${ }^{37}$

Respecto de la libertad de misión tenemos la siguiente cita:

Otro título puede invocarse, a saber, la propagación de la religión cristiana. A favor del cual sea la primera conclusión: Los cristianos tienen el derecho de predicar y de anunciar el Evangelio en las provincias de los bárbaros:... Porque si tienen derecho a peregrinar por aquellos lugares y comerciar con sus gentes, pueden también enseñar la verdad a los que la quiera oír... porque de otro modo estarían fuera del estado de salvación, si no fuera lícito a los cristianos irles a anunciar el Evangelio... la corrección fraterna es de derecho natural, como el amor. Y como ellos no sólo están en pecado, sino también fuera del estado de salvación, compete a los cristianos corregirlos y dirigirlos; más aún, parece que hasta están obligados a ello... Aunque esto sea común y lícito a todos, pudo, sin embargo, el Papa encomendar este asunto a los españoles y prohibírselo a los demás... si de otras naciones cristianas concurriesen indistintamente a aquellas provincias, es fácil que mutuamente se estorbaran y surgiesen muchas disensiones, por donde se impediría la tranquilidad y se turbaría el negocio de la fe y conversión de los bárbaros. Además, puesto que los príncipes españoles fueron los primeros que, bajo sus auspicios y con su dinero, tomaron sobre sí aquella navegación y descubrieron felizmente el nuevo mundo, justo es que tal peregrinación se prohíba a los demás y ellos solos gocen de lo descubierto... Si los bárbaros, ya sean sus jefes, ya sea el pueblo mismo, impi- 
dieran a los españoles anunciar libremente el Evangelio... hacen los bárbaros injuria a los cristianos... luego, tienen ya éstos justa causa para declarar la guerra... es lícito a los españoles ocupar sus tierras y provincias, establecer nuevos señores y destituir a los antiguos, y hacer las demás cosas que por derecho de guerra son lícitas en toda guerra justa. ${ }^{38}$

Bien, pues aquí tenemos la explicación de Vitoria para desencadenar la guerra justa. Nunca estará por demás mencionar que para entonces ya había desaparecido la mayor parte de la población india en el Caribe y estaba perpetrándose una dramática disminución también de la población india en México de 1,5 millones entre 1519 y alrededor de $1650 .{ }^{39}$

\section{Discusión sobre la guerra justa}

El arraigo escolástico de la interpretación vitoriana y la elaboración de sus títulos jurídicos se basan en una objetividad ahistórica, pues el nuevo mundo no parece ser para Vitoria un hallazgo relevante ni moral ni políticamente. El acontecimiento es asimilado y abstraído a conceptos y medidas inalterables del razonamiento escolástico: "La exposición escolástica se mantiene a una distancia normativa general de las circunstancias. Sus tesis se refieren únicamente a argumentaciones discutibles, y sus conclusiones no se centran directamente en el caso histórico concreto y no lo deciden en absoluto a modo de sentencia judicial". ${ }^{40}$

El encargo papal de misión constituye, indirectamente, a través de la construcción de la guerra justa, otro título jurídico de la Conquista, junto al título real: el hecho del descubrimiento, que Vitoria considera como ilegítimo. Al ser el trabajo de misión el tema central: "En este sentido, la argumentación de Vitoria aún se apoyaba totalmente en la ordenación del espacio del Derecho de Gentes de la Respublica Christiana que se basaba en la distinción del suelo de los soberanos y pueblos cristianos". ${ }^{41}$

Por ningún motivo el libre comercio defendido por Vitoria lo hace un pensador moderno, o adscrito al principio liberal comercial, o visionario del Lebensraum, aún cuando sienta las bases que no tenían las guerras coloniales: "El comercio es un mero medio de la época anterior a la

38 Ibidem, pp. 65 y 66.

39 Wallerstein, Immanuel, El moderno sistema mundial I. La agricultura capitalista y los origenes de la economía-mundo europea en el siglo XVI, 10a. ed., México, Siglo XXI, 2003, p. 124.

40 Schmitt, Carl, op. cit., nota 15, p. 85.

41 Ibidem, p. 87. 
técnica. La libertad de misión, sin embargo, es una libertas de la Iglesia cristiana, y en el pensamiento y el lenguaje medieval, libertas era equivalente a derecho. Así pues, la Europa cristiana aún es para Vitoria un centro de la tierra y está arraigada históricamente de modo muy concreto, en Jerusalén y Roma". ${ }^{42}$

Sobre la base de la diferencia esencial entre cristianos y paganos, Vitoria adscribe su guerra justa al ordo medieval, entendiendo la propagación del evangelio como un derecho. El problema es que la misión se llevaba a cabo en territorios libres para la ocupación europea. Esa libertad implicaba violencia. La argumentación indirecta de justificar y legalizar la guerra a partir de la resistencia a la prédica y al libre comercio, permite a Vitoria al tiempo de liberar su objetividad teológico-moral, le impide discriminar de manera directa a los bárbaros infieles. Sin embargo, con esto basta para entender que sus títulos ilegítimos quedan implícitos en el orden medieval y subyacen a su pensamiento. Sumemos a éste los títulos que expresamente declara como legítimos.

En la formulación teológico-moral al margen de toda censura y discriminación, Schmitt encuentra el empleo posterior de la argumentación vitoriana: el traslado de "sus frases teológico-morales a un conjunto de exposiciones construidas de otro modo, no teológicas, es decir, puramente morales o puramente jurídicas... muchos argumentos de Vitoria pueden ser aislados del problema histórico concreto". ${ }^{43}$ Se olvida entonces, que como teólogo español, había expuesto la cuestión católica española, en el ámbito estricto de su órden y de la unidad política del imperio español católico. ${ }^{44}$

Es en el marco de la argumentación teológico-moral y eclesiástica en la que debe explicarse la autoridad de la Iglesia cuando determinaba guerras justas con base en iusta causa. En el derecho de gentes interestatal, bajo la argumentación jurídico-formal los nuevos protagonistas, los Estados en igualdad de derechos, habrán de contemplarla sobre la base de la determinación del iustus hostis.

42 Ibidem, p. 91.

43 Ibidem, pp. 91 y 92. Respecto de la actualización del pensamiento vitoriano, tenemos que James Brown Scott, fundador del American Institute of International Law y de la American Society of International Law, apoyó algunas de sus conferencias en teólogos españoles como Vitoria y Suárez, proclamándolos fundadores del derecho de gentes. Ibidem, p. 97.

44 Ibidem, p. 93. 


\section{CONCLUSIÓN}

Los pecados de los indios, la renuncia de éstos a abrazar la fe cristiana, el no dominio universal del emperador y tampoco la autoridad universal y temporal del sumo pontífice, cuatro de los títulos consideradas por Vitoria como ilegítimos, hacen deducible en apariencia, sobre todo a partir de los dos primeros, que la condición de no español y no cristiano (hoy no occidental) supone no obstante, el reconocimiento (por suerte) de que los indios son personas, con libertad, capacidad jurídica e iguales en derechos a los españoles. Según lo anterior, la implícita defensa a los indios según la postura teórica vitoriana, dista en realidad de serlo, al considerarlos por otro lado, violadores de títulos que él formula como legítimos, al tiempo de cometer injuria por oponerse al cristianismo y al libre comercio.

No obstante, habrá que reconocer lo meticuloso que fue Vitoria al no criminalizar directamente a los indios, posición que ciertamente, como sostiene Schmitt lo aproxima al nuevo derecho de gentes interestatal. La iusta causa característica de la escolástica para entablar guerra justa ha pretendido racionalizarse por el iustus hostis del moderno derecho interestatal. Y me refiero a una pretensión racional que hoy se manifiesta en acciones policiales aplicadas a criminales perseguibles por doquier. Con lo anterior, la iusta causa queda en el aire y el iustus hostis pasa a ser un método discriminatorio.

La novedad del pensamiento vitoriano radica pues, en la formulación de títulos basados en el derecho natural común a todas las naciones como el libre comercio que esgrime, apartándose en apariencia y sólo en apariencia de la raigambre medieval, pues la tarea de misión es característica del Medievo. Así, es la interpretación moderna de su pensamiento la que lo adscribe a los nuevos tiempos.

De acuerdo con lo anterior, la abundante literatura sobre Vitoria, sobre su defensa a los indios y como fundador del derecho internacional, contrasta con la violencia sin tasa que caracterizó la ocupación del continente americano sin las aporías que supondría la ausencia de todo marco legal que sancionara la explotación. Cuando hubo de contarse con dicho marco legal, en nada se remedió aquella violencia (que en todo caso no era lo que el título legal pretendía) y sí en cambio se establecieron las bases de cómo llevar a cabo guerras justas, legalmente previstas. 
Es lo anterior, una parte de la esencia del moderno derecho internacional inaugurado por el descubrimiento: garantizar nuevas posiciones a potencias europeas - en particular a España-—que vieron en América una oportunidad inmejorable, hasta la fecha irrepetible en la historia del mundo.

Por otro lado, la actualización del pensamiento de Vitoria nos da una idea de lo caprichoso que se ha tornado el empleo del término guerra justa, en situaciones descontextualizadas del orden concreto en el que se formuló. Motivo ya de exámenes exhaustivos es la guerra justa entre los modernos. Sin embargo, el legado de este pensador y el impacto de su discurso fue invaluable para España y Europa, y lo sigue siendo para los grandes actores políticos del siglo XXI, que emprenden sus conquistas seglares con el trabajo de Vitoria.

\section{BIBLIOGRAFÍA}

Bartolomé de las Casas, Tratados, México, FCE, 1997, t. II, Biblioteca Americana, núm. 42.

BeníTEZ, Fernando, La ruta de Hernán Cortés, 2a. ed., México, FCE, 1956.

BERMAN, Harold, J., La formación de la tradición jurídica de Occidente, México, FCE, 1996.

CASTAÑEDA, Paulino, "La interpretación teocrática de las bulas alejandrinas", Anuario Mexicano de Historia del Derecho, México, UNAM, Instituto de Investigaciones Jurídicas, vol. V, 1993.

DE AQuino, Tomás, Tratado de la ley, tratado de la justicia, gobierno de los príncipes, México, Porrúa, 2000.

De Vitoria, Francisco, Reelecciones del estado, de los indios y del derecho de la guerra, México, Porrúa, 1996.

GRIGÓleVICH, J., La iglesia católica y el movimiento de liberación en América Latina, Moscú, Progreso, 1984.

MARGADANT, Guillermo, La segunda vida del derecho romano, México, Porrúa, 1980.

SchmitT, Carl, "El Nomos de la tierra. Cinco corolarios a modo de introducción”, varios autores, Carl Schmitt, Teólogo de la política, México, FCE, 2001. 
_ El Nomos de la tierra en el "derecho de gentes del Ius publicum europeam”, trad. de Dora Schilling Thou, Granada, Comares, 2002.

SEPÚlVEDA, Juan de, Tratado sobre las justas causas de la guerra contra los indios, México, FCE, 1996.

— Suma Teológica de Santo Tomás de Aquino, trad. de Francisco Barbado Viejo, Biblioteca de Autores Cristianos, Universidad de Salamanca, Madrid, MCMLIX, t. VII.

WALLERSTEIN, Immanuel, El moderno sistema mundial I. La agricultura capitalista y los orígenes de la economía-mundo europea en el siglo XVI, 10a. ed., México, Siglo XXI, 2003.

Weckmann, Luis, Constantino el Grande y Cristóbal Colón. Estudios de la supremacía Papal sobre islas, 1091-1493, 2a. ed., México, FCE, 1992.

— El pensamiento político medieval y los orígenes del derecho internacional, 2a. ed., México, FCE, 1993. 